\title{
O Aval
}

Newton de Lucca

Professor Assistente-Diretor do Departamento de

D. Comercial da Faculdade de Direito da USP

ROTEIRO: 1) INTRODUCAO; II) FUNCEES; III) CONCEITO; IV) FORMA; V) REFERENCIAS HISTORICAS.

\section{Introdução}

A obrigação decorrente do aval é uma obrigação cambial de garantia assumida pelo «avalista» em favor do «avalizado». Embora seja um instituto típico do direito cambiário, o aval constitui uma forma de garantia pessoal bastante difundida entre os títulos de crédito em geral, não se limitando a sua aplicação à letra de câmbio e à nota promissória (títulos cambiais ou cambiários), nem tampouco aos cheques e às duplicatas (títulos «cambiariformes»), mas, igualmente, a outros títulos que, pelo fato de serem documentos necessários para o exercício do direito literal e autônomo neles mencionado, são considerados «títulos de crédito».

Diz-se que o aval dá lugar a uma obrigação «autônoma». Tal significa que a sua validade não está condicionada à validade da obrigação garantida.

Ainda que nula a obrigação garantida, subsiste o aval, a não ser que haja um vício de forma do título. Daí dizer-se que existe no instituto do oval tanto a autonomia substancial quanto a acessoriedade formal. cípios:

$\mathrm{O}$ art. 32 da Lei Uniforme consagra exatamente esses dois prin-

«O dador de aval é responsável da mesma maneira que a pessoa por ele afiançada.

A sua obrigação mantém-se, mesmo no caso de a obrigação que ele garantiu ser nula por qualquer razão que não seja um vício de forma).

A obrigação do avalista é, destarte, na precisa observação de MESSINEO (1),

(1) Manuale di Diritto Civile e Commerciale, Giuffrè, 1972, pág. 368. 
«subsidiária, enquanto o seu pressuposto indispensável é a exigência de uma outra obrigação, que seja «formalmente» válida, e à qual ela se reporta; mas por outro lado, tal obrigação, como foi dito, é autônoma, como toda outra obrigação cambiária, e segue a própria sorte, independente da obrigacão garantida (do avalizado)».

Do que foi exposto resulta, igualmente, que o aval não se confunde com a fiança. A tradução brasileira da Lei Uniforme foi lamentável. No texto francês, está empregada a palavra «garant» que não deveria ter sido traduzida por "afiançada», conforme anotara o Prof. RUBENS REQUIÃO ${ }^{(1)}$. No caso da fiança, como é sabido, a nulidade da obrigação afiançada atingiria a própria garantia, nos termos da lei civil.

Cumpre aduzir, todavia, que a diferença apontada não significa que os princípios da fidejussão não possam ser subsidiariamente aplicáveis ao aval enquanto compativeis com a autonomia das obrigações cambiárias e com os outros principios do direito cambiário, conforme lembra oportunamente ASQUINI ( ${ }^{2}$ ).

Escusava salientar, talvez, que não será nossa intenção, por certo, outorgar ao presente trabalho o cunho de um tratamento sistemático e completo sobre o instituto do aval. Pelo contrário. As numerosas citações e transcrições dos autores, quer dos nacionais, quer dos alienígenas (que, às vezes, tornam excessivamente monótona a leitura para os espíritos mais ávidos de «construções jurídicas novas»), apenas se destinaram a facilitar a pesquisa do leitor que deseja se enveredar pelos meandros tortuosos do aval.

$\mathrm{Na}$ verdade, sem que as diferentes partes sejam consideradas premissas para o que se pretendeu concluir no derradeiro capítulo, nos moldes de um silogismo, visaram elas, a par de dar certa visão panorâmica do instituto - tão necessário ao desenvolvimento da pesquisa jurídica - a propiciar alguns subsídios para que, em termos de autonomia do aval, possa esse fenômeno se convenientemente entendido. Parecendo necessário que, a partir da fixação do princípio da autonomia substancial do aval, sejam extraídas as consequiências práticas de tal posição, julgamos oportuno analisar, em nossas linhas conclusivas, recente decisão do Tribunal de Alçada Civil que, embora calcada em argumentação aparentemente poderosa, discrepa, fundamentalmente, não apenas da jurisprudência dominante sobre a matéria como também dos próprios resultados obtidos pela elaboração doutrinária do instituto do aval.

Estes últimos, atualmente estampados na doutrina mais moderna, que vislumbra no aval uma «garantia cambiária típica», indicam que

(1) Curso de Direito Comercial, 9* edição, Saraiva, $2^{\circ}$ vol., pág. 346.

(2) «Titoli Di Credito», Casa Editrice Dott. Antonio Milani, 1966, pág. 258. 
o avalista adquire, com o seu ato, uma obrigação de caráter pessoal e direto, quase inteiramente desvinculada da obrigação do avalizado, com a qual só manteria relação de forma, sendo sua responsabilidade essencialmente centrada no pagamento do título de crédito e não no adimplemento da obrigação própria do avalizado.

\section{Fungões}

Afirma VIVANTE (1) que

«o aval é uma garantia nas formas cambiárias, acrescentando que ele não faz parte do nexo normal de uma cambial que pode cumprir inteiramente a sua função na circulação sem o aval».

Arremata-nos VIVANTE que

«se todas as assinaturas da cambial são sólidas, não haveria necessidade de avais que representam um sinal de pouco crédito para os que deles necessitam.»

Não há como negar razão ao grande jurista italiano, sob um ponto de vista estritamente lógico. $\mathrm{Na}$ atividade negocial moderna, porém, embora a instituição do aval continue a cumprir a mesma função de outrora no sentido de garantir o pagamento, não significa que a exigência de aval seja sinal de pouco crédito para o emitente.

A atividade bancária de nossos dias demonstra, à sociedade, que o aval é um reforço de garantia sempre exigido, ainda que não se acredite no inadimplemento da obrigação por parte do emitente.

$\mathrm{E}$, sob tal enfoque, não pode deixar de ser assinalado que o aval cumpre importante função econômica no que se refere à circulação de riquezas uma vez que, valorizando a confiança, facilita o trespasse do documento entre diversos tomadores.

H. ALEGRIA afirmou, a propósito, $\left(^{1}\right)$ que

«o aval não é visto hoje como desfavor nem como sinal de ausência de crédito, senão como precaução normal $\Theta$, às vezes, como valorizador da firma do devedor avalizado que inspira confiança de tal grau que merece sua exteriorização cambiária objetiva em um ato de pura garantia».

Parece importante determo-nos, por alguns instantes, nessa função de garantia que é exercida pelo aval.

Qual é a razão pela qual o credor cambiário exige a prestação do aval? Claro está que ele deseja estar garantido quanto ao seu crédito, vale dizer, quer ele ter a certeza ou, pelo menos, ter o mais elevado grau de probabilidade de que o seu crédito venha a ser integralmente satisfeito.

(1) «Trattato di Diritto Commerciale», vol. III, pág. 317, no 1221.

(1) «El Aval», Buenos Aires, Editorial Astrea, 1975, pág. 5. 
Tão extensa é a garantia prestada pelo aval que a Lei chegou mesmo a estabelecer, como se viu, que o aval subsiste ainda que nula a obrigação do avalizado.

A gravidade da afirmação poderia, no leitor desprevenido, causar até mesmo certa perplexidade. Quais as razões que estariam a justificar a subsistência de uma obrigação que visa a garantir uma outra que é fulminada de nulidade pela ordenação jurídica? Caberia, então, perguntar.

A resposta, entretanto, não é difícil para aqueles que, ao pensarem nos títulos de crédito, nunca perdem de vista a predominante função de circulação de tais títulos. Se toda a construção doutrinária dos títulos de crédito teve como preocupação propedêutica facilitar a circulação das riquezas, daí resultando todo o fenômeno da inoponibilidade das exceções extracartulares em relação ao terceiro portador boa-fé, torna-se de perceptibilidade imediata que o aval desempenha 0 papel de colaborador nessa função de circulação dos títulos.

O que se quer, em última análise, é sempre dar ao credor cambiário a maior convicção possivel quanto ao recebimento da soma indicada no título.

Essa idéia é tão cristalina que, por outro lado, se a nulidade decorrer de vício de forma, deixa de subsistir a obrigação do avalista, conforme diz a Lei.

Por que, nesse caso de vício de forma, deixa o aval de subsistir? Exatamente pela razão de que, se se trata de vício de forma, o $3^{\circ}$ portador poderia ter identificado o vício por acasião do recebimento do título.

A situação é a mesma da que ocorre com o mecanismo geral das exceções.

Sabemos que, referentemente aos vícios do negócio de emissão, haverá inoponibilidade das exceções a quem não tenha participado dessa relação de emissão. A razão é simples.

Se o adquirente é um estranho à relação de emissão - e exatamente por isso inteiramente ignaro das eventuais exceções existentes - como poderia ele defender-se eficazmente dessas últimas?

Vemos, portanto, que a função da autonomia substancial do aval é a mesma da autonomia existente na tradição doutrinária dos títulos de crédito, vale dizer, tem como propósito básico a proteção do $3^{\circ}$ portador de boa-fé, colocando-o a salvo de tudo aquilo que esteja no plano extracartular.

Assim como a autonomia não vai até o ponto de tornar inoponível um vício de forma - já que, nesse caso, não há falar-se em $3^{\circ}$ ignaro do vício - também no aval, conforme vimos, a forma condiciona a subsistência do aval, vale dizer, se não existe vício de forma a autonomia do aval é tão ampla que a garantia subsiste até diante do caso extremo de nulidade da própria obrigação garantida. 


\section{Conceito}

BOLAFFIO ( ${ }^{1}$ ) escreveu que

«o aval é a garantia objetiva do pagamento total ou parcial da letra de câmbio, em favor de uma pessoa determinada que se chama avalizado, independentemente da obrigação garantida.»

Para esse autor italiano, o aval, como garantia objetiva, se diferencia da fiança onde existe uma garantia subjetiva.

VIVANTE $\left({ }^{2}\right)$ critica a qualificação de garantia «objetiva», feita por BOLAFFIO (e adotada, também, por autores de porte como BONELLI e MESSINEO) alegando duas razões que considerou «decisivas» para condenar tal expressão:

«a) que o aval sucumbe se a obrigacão do avalizado é inexistente;

b) que o aval garante somente os obrigados posteriores ao avalizado; se este paga, o avalista não responde mais pelo pagamento da cambial.»

Voltaremos a esse ponto nas linhas finais do presente capítulo. Passemos, agora, não obstante o caráter enfadonho das transcrições, aos outros autores que conceituaram o instituto do aval.

ASQUINI ( ${ }^{3}$ ) considera o aval como

«declaração cambiária com a qual alguém (avalista) garante cambiariamente o pagamento da cambial para um outro obrigado cambiário (avalizado).

Sobre a base de tal declaração, e condicionalmente à sua entrada em circulação (desapossamento do título) - prossegue ASQUINI -

«cada sucessivo portador do título é legitimado para exercitar, de modo autônomo, perante o avalista, o direito mencionado no título (pagamento da soma cambiária), quaisquer que sejam as relações intercorrentes entre avalista e avalizado e entre avalista e os precedentes possuidores do título

MESSINEO ( ${ }^{1}$ ) considera o aval uma

«declaração de vontade cartular, unilateral e abstrata, enquanto desvinculada da relação fundamental intercorrente entre avalista e avalizado; ela dá origem a uma obrigação de garantia, ou seja, a uma promessa de pagar, no lugar e na posição do avalizado (obrigado principal ou obrigado de regresso).»

(1) Apud VIVANTE, ob. cit., vol. 3, pág. 318, nota de rodapé no 217.

(2) Idem, ibidem.

(3) Ob. cit., pág. 257.

(1) Ob. cit., pág. 368 . 
DE SEMO (2) define o aval como

"uma garantia pessoal, tendo caráter formalmente acessório, dada sobre o título para o pagamento da cambial, em favor de um obrigado, e em razão da qual o avalista assume a posição do avalizado, vinculando-se solidariamente junto com ele e com os demais signatários perante o portador.»

Entre os autores franceses, embora não se possa perceber pelas conceituações a seguir transcritas, há nítida tendência de aproximar o aval da fiança, dependente da obrigação principal, conforme anota, com propriedade, BONFANTI-GARRONE ( ${ }^{3}$ e RUBENS REQUIÃO $\left({ }^{4}\right)$, 0 mesmo acontecendo, de certa maneira, com o direito espanhol ${ }^{(5)}$.

Para ROBLOT (1) o aval é

«a obrigação assumida por uma pessoa de pagar um efeito de comércio no vencimento, nas mesmas condiçoés que um outro subscritor que, precedentemente, tenha aposto sua assinatura sobre o título.»

PERCEROU e BOUTERON (2) explicam o aval como

«uma garantia pessoal do pagamento da letra de câmbio que acresce, como o aceite, mais um devedor ao titulo."

E RODIÈRE ( $\left.{ }^{3}\right)$, finalmente, vê no aval

«uma caucão solidária do signatário da letra de câmbio.»

Entre os autores latino-americanos, merecem destaque, entre outros, os nomes de RIVAROLA, FERNANDEZ, ÉCTOR ALEGRIA, MUÑOZ, JAUREGUIBERRY, etc.

RIVAROLA ( ${ }^{4}$ ) afirma que

«o aval não é uma fiança nem qualquer das garantias do direito comum, senão, como o diz o Código de Comércio Argentino, uma obrigacão especialíssima, que somente pode subsistir no regime legal da letra de câmbio ou no dos papéis do comércio à ordem, assimilados àquela.»

(2) Ob. cit., pág. 453.

(3) «De los Titulos de Credito», Abeledo-Perrot, Buenos Aires, 2* edição, pág. 404.

(4) «Curso de Direito Comercial», Saraiva, 99 edição, 1980, $2^{\circ}$ volume, pág. 346.

(5) Entre os países latino-americanos, a legislação cambiária que mais aproxima o aval do instituto da fianca é, sem dúvida, a do Chile. O art. 680 do Código Comercial Chileno reza que:

....uel aval es un acto escrito en vertud del quo un tercero extraño a la letra de cambio afianza solidariamente el pago de ella en los términos y bajo las condiciones estipuladas o en los mismos en que se haya obligado la persona afianzada» (grifos nossos).

(1) «Les Effets de Commerce», Sirey, 1975, Paris, pág. 204.

(2) Apud RUBENS REQUIÃO, ob. cit., págs. 345 e 346.

(3) «Droit Commercial», Dalloz, 1975, pág. 69.

(4) «Letra de cambio, cheque y demás papeles de cambio», Buenos Aires, 1944, tomo II, pág. 324 . 
Para FERNANDEZ (5) o aval é

«um ato jurídico unilateral, abstrato, de natureza cambiária, que obriga de forma autônoma, distinta e pessoal a quem a pratica (avalista) ao pagamento da obrigação cartular.» .. . .

\section{HÉCTOR ALEGRIA ( ${ }^{1}$ ) define o aval como o}

«ato unilateral não receptício de garantia, outorgado por escrito no título ou fora dele, em conexão com uma obrigação cartular formalmente válida, que constitui o outorgante em responsável cambiário do pagamento.» do aval:

LUIZ MUÑOZ (2) nos oferece uma definição demasiado longa

«Es el aval un negocio jurídico unilateral de garantia objetiva $y$ personal, $y$ de afirmación de derechos, total o parcial, accesorio y subsidiario que consiste en una sola declaración de contenido volitivo procedente de una sola parte o esfera interesses llamada avalista, vinculante, recepticia dirigida a persona incierta, sin libertad de forma, pero sin que ésta sea sacramental, que demuestra o prueba la garantia y afirmación de derechos, constitutiva puesto que crea la garantia y la afirma, dispositiva porque se precisa del documento donde conste para hacer efectivo el aval, y literal, autónomo, abstracio desde el punto de vista formal y legítimamente, ya que por acceder a la letra de cambio reúne los caracteres de ella, y en vertud del cual el avalista se obliga eventual, incondicional, pero solidariamente, en los mismos términos que aquel por quien se otorga el aval $y$ en el mismo lugar y grado (art. 34), al pago, por lo que el aval pueda ser principal si se avala al girado, y de regresso cuando se avala a los obligados de esa índole (art. 32).»

\section{JAUREGUIBERRY $\left({ }^{3}\right)$ escreve que o aval}

«es una obligación de garantia, objetiva porque está referida al pago total ou parcial de una letra de cambio, y personal porque se otorga a favor del avalado, que siempre es un obligado cambiario, y además no crea ningún derecho real de garantia.»

Entre os autores nacionais, são menos numerosas as conceituações do instituto.

(5) Apud BONFANTI-GARRONE «De los títulos de Credito», Abebedo-Perrot, Buenos Aires. $2^{\mathfrak{a}}$ edição, 1976, pág. 405.

(1) Ob. cit., pág. 12. BONFANTI-GARRONE adotam em sua obra (Ob. c̀it., pág. 403) a citada definição de ALEGRIA.

(2) «Titulo-Valores», Tipografia Editora Argentina, Buenos Aires, 1973, 2" edição, pág. 468.

(3) $\mathrm{MUNOZ}$, ob. cit., pág. 469. 
EUNAPIO BORGES ${ }^{1}$ ), em conceito que precisa o caráter teleológico, ensina que

«o aval - instituição de direito cambial - tem por finalidade garantir o pagamento da letra de câmbio e da nota promissória, assim como de outros títulos (cheques e duplicatas) em parte assimilados aos cambiais».

RUBENS REQUIÃO (2) assinala que

«o aval é a garantia de pagamento da letra de câmbio, dada por um de seus signatários».

MAGARINOS TORRES (3), ao cuidar do aval na nota promissória, definiu-o como

«a garantia pessoal, plena e solidária, que se pode juntar na nota promissória à obrigação de qualquer dos coobrigados».

LACERDA $\left({ }^{4}\right)$ explicou que

«o aval é obrigacão cambiária autônoma, e de garantia solidária à do obrigado ao qual adere».

CARVALHO DE MENDONÇA (5) afirmou que

«o aval é a garantia prestada em forma cambial ao pagamento da letra de câmbio».

PONTES DE MIRANDA (6) assim explica o instituto:

«o direito cambiário conhece obrigação típica, que é literal e expressa: o aval. Constitui ele uma das obrigacõos por declaração unilateral de vontade, com efeitos absolutos, por figurar no título cambiário, a favor de todos os possuidores, da generalidade, se bem que seja obrigação equiparada, reforço, sustentáculo de alguma das obrigações pessoais insertas no título. Há sempre obrigado, a que o avalista se equipara, mas as exigências formais o materiais do direito cambiário extremam de qualquer garantia pessoal a obrigação daquele que avaliza chamado, neologisticamente, em portuguê, avalista - a obrigação de outrem, que se diz o avalizado.» (grifos do autor)

Embora o elenco reproduzido deixe patenteada a diversidade de opinióes do conceito do aval, reconhece-se, de maneira geral, a caracte-

(1) «Do Aval», Forense, 4 edição, 1975, pág. 15.

(2) Ob. cit., pág. 345.

(3) «Nota Promissória», Saraiva, 1943, 54 edição, pág. 211.

(4) «A Cambial no Direito Brasileiro», Editora de Leite Ribeiro \& Maurillo, Rio de Janeiro, 1921, 3q edição, pág. 149.

(5) «Tratado de Direito Comercial Brasileiro», vol. V, 2" parte, 1922, Rio de Janeiro, pág. 347, § 747 .

(6) «Tratado de Direito Cambiário», vol. I, Letra de Câmbio, Max Limonad, 1954, 2* edição, pág. 245 . 
rística básica de ser o instituto uma obrigação cambiária autônoma. Vejamos, agora, a divergência conceitual, de início apontada, no tocante ao aval considerado como garantia «objetiva».

Parece-nos que a noção de garantia «objetiva» não serviu para trazer maiores luzes ao instituto ,já que a doutrina não precisou o alcance que se pretende dar com a utilização de tal expressão. Seria para dizer que a garantia não se ligaria à firma do avalizado e sim ao título em si mesmo considerado? Ou seria simplesmente para distinguir o instituto da fiança onde existe uma garantia de cunho subjetivo?

Sob esse segundo aspecto, não vemos como poderia ser contestado o caráter «objetivo» do aval que não se confunde, efetivamente, com a fiança, mas, adotada a acessoriedade formal do aval, como, aliás, o foi na Lei Uniforme, como sustentar-se que a garantia não se ligaria à firma do avalizado e sim ao título? Se ao asseverar-se que a garantia não se liga à firma do avalizado pretende-se dizer que a obrigação do aval subsiste, ainda que inexistente a firma do emitente, não há como aceitar-se, à luz da Convenção Genebrina, tal «objetividade» do aval.

Se, entretanto, por garantia «objetiva» queremos designar, quer uma obrigação inteiramente desvinculada do caráter subjetivo que existe na fiança, quer uma obrigação de cunho substancialmente autônomo parece-nos irrecusável a propriedade de tal expressão.

\section{Forma}

A forma pela qual o aval é prestado, nos títulos cambiais, está disciplinada pelo art. 31 da Lei Uniforme:

«O aval é escrito na própria letra ou numa folha anexa. Exprimi-se pelas palavras «bom para aval» ou por qualquer fórmula equivalente; e assinado pelo dados do aval.

$O$ aval considera-se resultante da simples assinatura do dador aposta na face anterior da letra, salvo se se trata das assinaturas do sacado ou do sacador.

$O$ aval deve indicar a pessoa por quem se dá. Na falta de indicação, entender-se-á pelo sacador».

Nota-se que o artigo supratranscrito, em pleno vigor entre nós, apresenta diferenças em relação ao art. 14 do Decreto $n^{\circ} 2.044$, anteriormente vigente:

«O pagamento de uma letra de câmbio, independente do aceite e do endosso, pode ser garantido por aval. Para a validade do aval, é suficiente a simples assinatura do próprio punho do avalista ou do mandatário especial, no verso ou no anverso da letra».

Conclui-se, portanto, que a simples assinatura, no anverso da letra, é suficiente para a configuração do aval em ambos os diplomas legais. 
A simples assinatura no verso da letra, porém, só seria suficiente para a validade do aval no regime do retrotranscrito art. 14 do Decreto $n^{\circ}$ 2.044. Pelo art. 31 da Lei Uniforme, conforme vimos, é necessária a menção «bom para aval» ou outra a ela equivalente, quando se trata de assinatura aposta no verso do título.

Não prevaleceu na Convenção Genebrina, destarte, a proposição de ARCANGELI e de PERCEROU, segundo a qual seriam sempre tidas como avais as assinaturas que não tivessem um outro papel cambiário.

Em consequiência, surge um intricado problema a ser resolvido quando a assinatura aposta no verso da letra não pode ser, de um lado, considerada como aval, por força da ausência de menção em tal sentido, e, de outro, não pode ser considerada como endosso em branco, por inexistir correspondência com a cadeia normal de transmissão do título.

Escusava dizer, talvez, que se a assinatura imaginada pudesse, nessa última hipótese, ligar-se à cadeia dos endossos sucessivos existentes, a mesma seria tida pura e simplesmente como endosso em branco sem maiores preocupações.

Mas, não sendo possível se atribuir à assinatura em questão a qualidade do endosso em branco, pela ausência de sua ligação com a cadeia de endossos existentes no título, qual é a significação que lhe devemos dar?

Basicamente, são três as posições que se formaram em torno do problema.

A primeira dessas posições, sustentada por uma plêiade invejável de juristas $\left.{ }^{1}\right)$, considera que a assinatura de que se cuida não poderá ser considerada como aval porquanto o aval deve ser prestado no anverso da letra ou, se prestado for no verso, existir a menção inequívoca que caracteriza a assinatura com essa qualidade.

Dentre os diversos autores, é ROSSI quem parece desenvolver, com profundidade dogmática, os argumentos sobre essa postura doutrinária.

(1) GUIDO ROSSI, in «L'avallo come garanzia cambiaria tipico», Milano, Giuffrè, 1962, págs. 105 e seguintes; DE SEMO, in «Trattato di Diritto Cambiario, Padova, Cedam, 1963, págs. 461 e 462; VALERI, Diritto Cambiario, II, no 204; ASQUINI, «Titoli do Credito», Padova, 1966, pág. 261; GUALTIERI, «I Titoli di Credit», Torino, 1953, Ed. Torinese, pág. 217; OPPO, «Banca e Credito Agrario», 1952, pág. 377. Extensa indicação dessa doutrina poderá ser encontrada em HECTOR ALEGRIA, «El aval - Tratamiento completo de su problemática jurídica», Astrea, Buenos Aires, 1975, pág. 142, nota de rodapé no 122. De notar-se, entretanto, que, entre os autores citados por ALEGRIA como partidários dessa corrente, está o nome de SALANDRA, o que nos parece evidente equívoco. Para o ilustre professor da Universidade de Pádua, não seduz a idéia de considerar a assinatura, nos casos em que estamos tratando, privada de valor cambiário, sendo preferivel considerá-la como aval (Cfr. «Curso de Derecho Mercantil», Trad. de Jorge Barrera Graf, Editorial Jus, México, 1949, pág. 278. 
Diz-nos esse grande autor italiano, após combater todas as outras posições, que:

«L'avallo è un instituto cambiario autonomo, per il quale il legislatore prescrive requisiti di forma precisi. Tali sono o la clausola di garanzia o la semplice firma sul recto della cambiale (posto dal legislatore, come ho detto, su un piano di parità).

Quando tali requisiti non siano soddisfatti, semplicemente non si ha avallo; né può l'interprete in tal caso introdurre prezunzioni (tanto più su questioni di forma), che lo stesso legislatore non ha creduto opportuno disporre. Nela nostra ipotesi non ritengo dunque che ci troviamo di fronto ad una lacuna, ma semplicemente ad un atto nullo per imperfezione formale. L'ipotesi è quella esattamente individuata dall' Oppo, di scritturazione materialmente incompleta che non può assumere valore cambiario» $\left.{ }^{1}\right)$

Assim, para os adeptos dessa corrente de pensamento, a assinatura prestada no verso, sem declaração de garantia, ficaria desprovida de qualquer valor cambiário pela sua insuficiência formal. Vale dizer: não será considerada nem aval, nem tampouco endosso branco.

Para uma segunda posição, defendida por STRANZ ( $\left.{ }^{2}\right)$,

«se a assinatura no verso, sem qualquer menção de garantia, não pode ser considerada nem aval e nem aceite, só poderia ser tida como um endosso em branco, ainda que não corresponda à cadeia de endossos existentes no título, porquanto se estaria diante de um problema de responsabilidade e não de interrupção da série de endossos».

\section{Observa ROSSI (1) que}

«se trata de uma tese parcialmente análoga à que foi acolhida pelo sistema anglo-americano, não sendo sustentável perante a Lei Uniforme no momento em que essa assinatura de que estamos a tratar não apresenta qualquer ligação com o nexo cambiário, interrompendo a série de endossas».

A própria jurisprudência alemã, todavia, manifestou-se contra a possibilidade de ser considerada como endosso em branco a simples assinatura no verso da letra.

Para uma terceira posição, a assinatura no verso da letra ainda que sem qualquer menção de garantia, deveria ser considerada como aval (desde que a mesma interrompa a cadeia de sucessivos endossos).

(1) Ob. cit., págs. 109 e 110.

(2) Apud ROSSI, ob. cit., pág. 108, nota de rodape no 33: «Blankoindossament als Wechselbitirgschaft»?, c. 1917.

(1) Ob. cit., pág. 108. 
Sustenta ANGELONI ( ${ }^{2}$ ) que

«ninguém apõe a própria assinatura numa cambial sem que tenha a intenção de assumir uma obrigação cambiária, sendo interesse do portador, por outro lado, que a cambial tenha um obrigado a mais».

Conclui esse autor com a consideração segundo a qualseria mais lógico atribuir a tal firma o valor de um aval antes de atribuir-lhe, sem necessidade, a função de destruir a regularidade da seqüência dos endossos.

ROSSI ( ${ }^{3}$ ) combate a posição de ANGELONI lembrando que

«nos encontramos diante de requisitos de forma no exame dos quais devem ser afastadas, da maneira mais catgórica, as considerações relativas à intenção do signatário. A simples firma aposta sobre o verso da cambial - prossegue ROSSI - não pode ser considerada, de modo algum uma firma de aval, uma vez que faltaria um requisito essencial de forma, qual seja o da cláusula de garantia».

Embora a posição de ROSSI seja prevalecente na maioria da doutrina, commespondendo, inclusive, ao pensamento de VIVANTE $\left(^{1}\right)$, a corrente que procura caracterizar a simples assinatura no verso da cambial (2) como aval parece ganhar novos adptos, sendo de destacar-se a cuidadosa reflexão de ALEGRIA $\left({ }^{3}\right)$, com novos e poderosos argumentos em favor dessa corrente $\left(^{4}\right)$.

\section{Referências Históricas}

EUN.ĀPIO BORGES ( ${ }^{5}$ ) assinalou, com propriedade, que

«a investigação histórica é menos proveitosa para o direito comercial do que para outros ramos do direito",

justificando tal assertiva, com base em ALFREDO ROCCO, na constante transformação do direito comercial, sendo

(2) Apud ROSSI, ob. cit, pág. 106.

(3) Idem, ibidem.

(1) «Trattato di Diritto Cambiario», vol. 3, Ed. Francisco Vallardi, 54 edição, 1935, págs. 318 e $319, \S 1222$.

(2) Com ressalva já feita anteriormente, como é óbvio, de que essa assinatura esteja interrompendo a série de endossos, sem o que não haveria a menor dúvida no sentido de considerá-la como endosso em branco.

(3) Ob. cit., págs. 145 a 150.

(4) Por refugir dos limites do presente estudo, estamos deixando de lado algumas posições singulares em relação ao problema, como, por exemplo, a de MOSSA, para quem uma simples firma sem declaração de aval, mas aderente ao endosso, vale como aval do referido endosso.

(5) Ob. cit., pág. 18. 
«relativamente muito escasso o número de normas e de institutos de origem remota cuja apreciação dependa de longas investigações históricas».

Poderíamos acrescentar, «ex-abundantia», que a observação do ilustre professor mineiro ganha particular intensidade no que se refere ao instituto dos títulos de crédito ao considerar-se que o mesmo era desconhecido do direito romano, fonte principal de nossa cultura jurídica.

No que diz respeito especificamente ao aval, registra CARVALHO DE MENDONÇA ${ }^{(1)}$ que

«o seu aparecimento teria ocorrido na segunda metade do século XVI, quando fora regulado pela Ordonnance du Commerce de 1673».

LOPES MUÑIZ $\left({ }^{2}\right)$, por outro lado, identifica o surgimento do aval, no ano de 1233, na Eigenwechsel (letra contra si mesmo) e, em 1359, na cambial tradicional.

Tais investigações históricas, evidentemente, são úteis ao estudioso na medida em que, com elas, compreender-se-á, de maneira mais adequada, certas peculiaridades desse instituto, conforme se mostrará a seguir.

Consta do interessante estudo realizado por SOLMI $\left({ }^{3}\right)$ que, ao final das feiras, eram apurados os débitos e os créditos de cada negociante, sendo as contas liquidadas mediante numerário ou por meio de letras de câmbio emitidas pelo devedor.

Nem sempre, havia plena confiança na pessoa do devedor, o que levava o credor a exigir, a título de garantia, uma outra letra de câmbio emitida por um banqueiro com sólida posição financeira.

Poderá ser vislumbrada, em tais explicações, não apenas a origem do aval prestado em documento separado, ainda hoje subsistente na legislação francesa, como a própria gênese do princípio da autonomia e da obrigação do avalista, como anota oportunamente o Prof. EUNAPIO BORGES $\left({ }^{4}\right)$.

De outro lado, cumpre lembrar que o referido estudo de SOLMI, desenvolvido a partir da monografia de ANGELONI (5) onde foi retomada, "ex-professor», a intrincada questão da natureza jurídica do aval, conclui por sugerir uma quarta (e, talvez, derradeira) opinião sobre a origem da palavra «aval».

(1) Ob. cit., Vol. $4^{\circ}, 2^{2}$ parte, no 747 , nota de rodapé iniciada na pág. 347.

(2) «História da La letra de cambio», pág. 5.

(3) «Sulla Origine Della Voce avallo», in Rivista di Diritto Commerciale, vol. 8๑, I, págs. 720 a 724 .

(4) Ob. cit., pág. 20 , nota de rodapé no 14.

(5) «La natura giuridica dell'avallo. Contributo alla dotrina dell'avallo», Torino, 1910. 
Para o ilustre professor da Universidade de Parma, o vocábulo «aval» derivaria, por um processo orgânico, do verbo «avallare», remontando-se a «advallare «(vallare), no sentido próprio de reforçar ou de munir com o «vallo», figuradamente transportado para o campo das garantias obrigatórias.

A tal ensinamento adere, entre nós, o Prof. EUNĀPIO BORGES $\left({ }^{1}\right)$ :

«Antes de SOLMI, o comercialista francês JULES VALERY apontara como provável a hipótese preconizada pelo professor italiano, a qual, a nosso ver, além de constituir a melhor explicação etimológica da palavra, é a que lança mais luzes sobre as origens e finalidades do próprio instituto».

Vejamos, rapidamente, as três explicações etimológicas anteriores para o vocábulo «aval».

Para a primeira delas, a expressão seria derivada da frase francesa «faire valoir» ou «à valoir», ou do equivalente latino «valere», no sentido de um ato que faz valer ou faz adquirir valor ao crédito cambiário garantido.

Trata-se da terminologia preferida, segundo SOLMI, pela velha doutrina francesa e, ainda, por alguns juristas modernos, italianos e estrangeiros.

Uma segunda explicação é sustentada por GRASSHOFF ( ${ }^{2}$ ), para quem o vocábulo derivaria da palavra árabe «hawâla» cuja significação, no antigo direito árabe, consistia numa obrigação de garantia assumida em favor de um terceiro, sob forma cambiária.

A terceira explicação, a que adere o Prof. ANGELONI

e seguida pela maior parte dos juristas, sugere que o termo «aval» derivaria do italiano «a valle», correspondente ao francês «àval», pelo fato de que a assinatura, destinada a garantir a cambial, vinha colocada abaixo, «in loco inferiori», ao pé do documento.

Tal discussão parece totalmente inócua no momento histórico em que vivemos, sendo muito mais uma questão da alçada dos filólogos do que dos juristas, como anota oportunamente SILVIA PINTO, já que o desbravamento etimológico, por certo, não trará qualquer subsídio à melhoria desse instituto jurídico.

(continua no próximo volume)

(1) Ob. cit., pág. 18.

(2) «Die suftága und hawâla der Araber», Göttingen, 1899, págs. 70 e seguintes, apud SOLMT, ob. cit., pág. 721. Informa-nos PAULO DA SILVA PINTO («Direito Cambiário», pág. 195) que tal explicação foi adotada por P. HUVELIN ( LL travaux récents sur l'histoire de la letrre de change»), 15 An. D. Com. (Fr.), 25. 